\title{
Open lateral internal sphincterotomy safe option for chronic anal fissure. A clinical study.
}

\footnotetext{
1. MBBS, FCPS

District Surgeon

DHQ Charsadda.

2. MBBS, FCPS

Associate Professor

LRH Peshawar.

3. MBBS, FCPS

Surgeon

DHQ Charsadda.

4. MBBS, FCPS

Medical Officer

DHQ Charsadda.
}

Correspondence Address:

Dr. Muhammad Bilal

District Surgeon

DHQ Charsadda.

drbilalmohd@yahoo.com

Article received on:

$11 / 06 / 2020$

Accepted for publication:

07/09/2020

\begin{abstract}
Muhammad Bilal', Viqar Aslam², Waqas Jan ${ }^{3}$, Zaheer ${ }^{4}$
\end{abstract}
\begin{abstract}
Objectives: To provide local data regarding the postoperative complications, pain, anal incontinence and recurrence after lateral internal sphincterotomy for chronic anal fissure. Study Design: Clinical Study. Setting: DHQ Charsadda. Period: May 2017 to December 2019. Material \& Methods: It was done on 230 chronic anal fissure patients who had underwent prior conservative treatment. Surgery for all patients was carried out under General anaesthesia with open sphincterotomy. Postoperative follow up was carried till 6 months. Data were collected and analysis by using SPSS version 23 . Chi square test was used to compare at level of significance $<0.005$. Results: Mean age of patients was $37.50 \pm 7.28$ years. Female presented with more postoperative complications than male but differences were statistically not significant. At the end of $6^{\text {th }}$ months follow up period we observed that significantly higher numbers of patients were satisfied $(91.4 \%)$ with a healing rate of $(93.8 \%)$. Conclusion: LIS is treatment of choice for chronic anal fissure.
\end{abstract}

Key words: Anal Fissure, Sphincterotomy, Surgical.

Article Citation: Bilal M, Aslam V, Jan W, Zaheer. Open lateral internal sphincterotomy safe option for chronic anal fissure. A clinical study. Professional Med J 2021; 28(2):137-140. https://doi.org/10.29309/TPMJ/2021.28.02.5190

\section{INTRODUCTION}

Lateral internal sphincterotomy (LIS) a surgical procedure introduced by Eisen-hammer, it has been considered standard treatment option for chronic anal fissure (CAF). Anal fissure (AF) is a small oval shaped tear in the skin that lines the opening of the anus extending below the dentate line up to the anal verge. It is of two types; acute and chronic. If the symptoms like severe pain and bleeding and along with that a sentinel skin tag on examination persists beyond 4-6 weeks then we refer to it as a chronic anal fissure. ${ }^{1-3}$

Both Medical and surgical treatment options are available. Treatment mainly aims at reducing the sphincter tone. ${ }^{3}$ American society of colon and Rectal surgeons guidelines promote Conservative or Medical treatment initially which includes high fibre diet, sitz bath, avoid getting constipated and applying GTN creams but for those majority of patients that do not respond to these treatments in those cases we opt for surgical interventions like LIS. It has healing rates reaching up to as high as $95 \%$ but it's more expensive than medical therapy. Moreover it is associated with a risk of long termpostoperative anal incontinence. Faecal incontinence after LIS varies widely from $1.3-30 \% .^{4-7}$

Due to unavailability of local studies, we have to rely on evidences provided by international studies which may not be applicable to our population due to different socioeconomic circumstances, illiteracy and availability of health care services. Therefore this study was conducted to provide local data regarding the postoperative complications, pain, anal incontinence, recurrence and success rate after LIS for CAF were recorded. So that better strategies can be planned to combat the problems related to LIS in our population.

\section{MATERIAL \& METHODS}

It is a cross sectional study conducted in general surgery department of tertiary care hospital (Charsadda) after the approval of Ethical Committee of the institution from May 2017 to December 2019. 230 Chronic anal fissure 
patients who had underwent prior conservative treatment. Patients suffering from anal fissure weeks, with exposed fibres of intern anilla were included and exclusion criteria was patients having simultaneous anal abscesses, anal fistula or haemorrhoidal diseases, already diagnosed inflammatory bowel disease and who underwent partial LIS.

The patients were selected by non probability convenient sampling method. Surgery for all conventent samplng method. surgery for all palients with open sphinction was given in the anoderm, the distal half of the internal anal sphincter was divided followed by closure of the mucosa. Internal anal sphincter was almost completely cut in LIS. The defect was not closed.

A questionnaire was given to the patients, pain was the significant factor to be evaluated and was evaluated by using visual analogue scale (VAS) in which numbering from 0 to 10 was given (VAS) in which numbering from 0 to 10 was given to patient on a ruler who chooses their level of No pain at all and when going from 0-10 the pain levels increases and 10 represented unbearable pain. All patients received $75 \mathrm{mg}$ of diclofenac sodium intramuscularly at the time of recovery and repeated when needed. Also validated scoring and grading was used to assess anal incontinence.

Anorectal examination was performed in every follow-up clinic visit (first, second, third, sixth and nine weeks and six months) and the fissure healing (pain relief and evaluation of the fissure, erythema and/or Inflammation), were recorded and analysed. All data was analyzed through Statistical package for social science (SPSS) version 23.Chi-square test was used to analyze data, as appropriate, and statistical significance was established at $p<0.005$

\section{RESULTS}

Total no of patient included in study were 230 . Out of total 218, (120 Male and 98 Female) completed the follow up. Male to female ratio was 1.2: 1 . Mean age of patients was $37.50 \pm$ 7.28 years. Postoperative complication details are described in Table-I. During follow up of six month duration the postoperative complications mere properly noted. Female presented with more postop noted. Female presented with managed but differences were statistically not significant. At the end of $6^{\text {th }}$ months follow up period we observed that significantly higher numbers of patients were satisfied (91.4\%) with a healing rate of (93.8\%).

Postoperatively the Pain Score (Median and Range) among the patients were analysed during the first, second, third, sixth and ninth weeks. Complete pain relief was observed in sixth week in both male and female. Every patient experienced different pain at different levels, though there was no significant difference in pain in both groups $(p=0.12)$. (Table-II)

\begin{tabular}{|c|c|c|c|}
\hline $\begin{array}{l}\text { Complications/ } \\
\text { complaints }\end{array}$ & $\begin{array}{c}\text { Male } \\
(n=120)\end{array}$ & $\begin{array}{l}\text { Female } \\
(n=98)\end{array}$ & P-Value \\
\hline Rectal Bleeding & $12(10 \%)$ & $11(11.2 \%)$ & 0.17 \\
\hline \multirow{3}{*}{$\begin{array}{l}\text { Hematoma } \\
\text { Wound Infection/ } \\
\text { Abscess } \\
\text { Incontinence }\end{array}$} & $3(2.5 \%)$ & $2(2.04 \%)$ & 0.18 \\
\hline & $2(1.6 \%)$ & $1(1.02 \%)$ & 0.83 \\
\hline & $2(1.6 \%)$ & $7(7.14 \%)$ & 0.07 \\
\hline Recurrence & $1(0.8 \%)$ & $7(7.14 \%)$ & 0.06 \\
\hline \multicolumn{4}{|c|}{$\begin{array}{l}\text { Table-I. Post-operative and follow-up complications/ } \\
\text { complaints }\end{array}$} \\
\hline \multirow{6}{*}{ Postoperative } & Week & Male & Female \\
\hline & First & $6(0-9)$ & $6(0-9)$ \\
\hline & Second & $5(0-8)$ & $5(0-8)$ \\
\hline & Third & $3(0-5)$ & $4(0-4)$ \\
\hline & Sixth & $0(0-0)$ & $0(0-0)$ \\
\hline & Ninth & $0(0-0)$ & $0(0-0)$ \\
\hline
\end{tabular}

Table-II. Pain Score (Median and Range)

\section{DISCUSSION}

The main aim of sphincterotomy was to reduce the anal sphincter pressure to improve the blood flow to the anoderm. The present study was conducted to determine in local population whether lateral internal sphincterotomy is an efficient surgical procedure for the treatment of $\mathrm{CAF}$ or not and what are the various associated complications.
The results of our study regarding pain relief are in accordance to the studies done by Vaithianathan et $a^{6}$ and Araujo et a ${ }^{7}$ had pain relief at the end of 6 th week. Like our study, Araujo et al ${ }^{7}$ did comparison of pain by visual analogue scale that underwent LIS.

LIS on one hand showing high rates of pain relief also has one very prominent disadvantage i.e Faecal incontinence (FI). In our study it was of mild severity $\mathrm{Fl}$ as documented by other publications. Results of studies by Mentes ${ }^{9}$, Arroyo ${ }^{10}$ and Nyam ${ }^{11}$ showed $95 \%, 92.5 \%$ and $96 \%$ healing rate on patients undergoing LIS respectively. rate on patients undergoing LIS respectively.

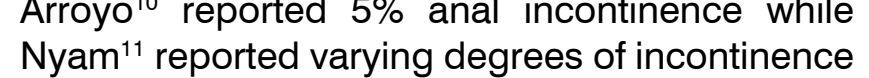
Nyam
after LIS.

There are many factors which seems to play an important role in the occurrence of FI after LIS such as age of the patient, Gender, anatomical differences of the perineal region, pregnancies and Vaginal deliveries, previous history of perineal surgery, inexperienced surgeons and inappropriate technique . $^{10-11}$

Our present study documented incontinence and recurrence rates associated with complete LIS and excluded the one's resulting from partial LIS. Only 9 patients of LIS surgery had gas/liquid incontinence out of which 6 patients symptoms resolved after 6 months without any intervention but the remaining 3 patients all of which were females and had previous history of vaginal delivery suffered from permanent incontinence.

Other complications such as wound infection, hematoma, anal abscess and fistula may also occur after LIS. In our study only 5 patients had perianal hematoma and 3 patients suffered from perianal abscess in early postoperative period while the most common complication recorded in the early period was rectal bleeding which in the early period was rect bleeding which required no intervention but the hematoma and abscess were relieved by draining them. Our present study supported the findings of other publications in which recurrence rate of LIS patients was $3.8 \% .^{9,10}$
The findings of the previous studies and present study are consistent with high patient's satisfaction rate. In Garcia- Granero et al ${ }^{12}$ study, this rate was 99\%. One study comr wo. with patients undergoing LIS in which $7 \%$ patien
in the LIS group were unsatisfied after LIS. ${ }^{4}$

Limitations of present study were that no comparison was made with other treatment methods, the surgery being performed not by one but by many different surgeons so different levels of surgical experience.

\section{CONCLUSION}

This study concludes that LIS is treatment of choice for chronic anal fissure.

Copyright $\odot 07$ Sep, 2020.

\section{REFERENCES}

Salih AM. Chronic anal fissures: Open lateral internal sphincterotomy result: A case series study. Ann Med
Surg (Lond). 2017; 15:56e58.

2. Vaithianathan $R$, Panneerselvam $S$. Randomised prospective controlled trial of topical $2 \%$ diltiazem treatment of chronic fissure in ano. Indian $J$ Surg. 2015; 77:1484e1487.

3. Nessar G, Topbas M. Lateral internal partial sphincterotomy technique for chronic anal fissure. Indian J Surg. 2017; 79: 185e187.

4. Brady JT, Althans AR, Neupane R, Dosokey EMG, Jabir MA, Reynolds HL, Steele SR, Stein SL. Am J Surg. 2017 Oct; 214(4):623-628, doi: 10.1016/j. amjsurg.2017.06.004. Epub 2017 Jul 5.

5. Emile SH. Indications and technical aspects of internal anal sphincterotomy: Highlighting the 2017; 60:128e132.

6. Vaithianathan $R$, Panneerselvam S. Randomised prospective controlled trial of topical $2 \%$ diltiazem treatment of chronic fissure in ano. Indian $J$ Surg. 2015; 77:1484e1487.

7. Araujo SE, Sousa MM, Caravatto PP, Habr-Gamai A, Cecconello I. Early and late results of topical diltiazem and bethanechol for chronic anal fissure: A compa 
8. Pescatori M, Anastasio G, Bottini C, Mentasti A. New grading and scoring for anal incontinence. Evaluation of 335 patients. Dis Colon Rectum. 1992; 35:482e487.

9. Mentes BB, Tezcaner T, Yılmaz U, Leventoglu S, Oguz M. Results of lateral internal sphincterotomy for chronic anal fissure with particular reference to quality of life. Dis Colon Rectum. 2006; 49:1045e1051.

10. Arroyo A, Pe'rez F, Serrano P, Candela F, Lacueva J, Calpena R. Surgical versus chemical (botulinum toxin) sphincterotomy for chronic anal fissure: Longterm results of a prospective randomized clinical and manometric study. AmJ Surg. 2005; 189:429e434.
11. Nyam DC, Pemberton JH. Long-term results of lateral internal sphincterotomy for chronic anal fissure with particular reference to incidence of fecal incontinence. Dis Colon Rectum. 1999; 42:1306e1310.

12. García-Granero E, Sanahuja A, García-Botello SA, Faiz O, Esclápez P, Espí A, Flor B, Minguez M, Lledó S. The ideal lateral internal sphincterotomy: Clinical and endosonographic evaluation following open and closed internal anal sphincterotomy. Colorectal Dis. 2009 Jun; 11(5):502-7.

\section{AUTHORSHIP AND CONTRIBUTION DECLARATION}

\begin{tabular}{|c|l|l|l|}
\hline Sr. \# & Author(s) Full Name & \multicolumn{1}{|c|}{ Contribution to the paper } & Author(s) Signature \\
\hline 1 & Muhammad Bilal & $\begin{array}{l}\text { Data collection, Analysis, } \\
\text { Interpretation. }\end{array}$ \\
2 & Viqar Aslam & $\begin{array}{l}\text { Research designing, Literature } \\
\text { review and drafting. } \\
\text { Data collection, Paper write-up. }\end{array}$ \\
3 & Waqas Jan & Study designing, Drafting. \\
\hline 4 & Zaheer & Staly & \\
\hline
\end{tabular}

